\title{
Adherence to COVID-19 Nutrition Guidelines Is Associated with Better Nutritional Management Behaviors of Hospitalized COVID-19 Patients
}

\author{
Amelia Faradina ${ }^{1}$, Sung-Hui Tseng ${ }^{2,3}$, Dang Khanh Ngan Ho ${ }^{1}$, Esti Nurwanti ${ }^{4}$ D, Hamam Hadi ${ }^{5,6,7}$ (D), \\ Sintha Dewi Purnamasari ${ }^{5,6,7}$, Imaning Yulia Rochmah ${ }^{8}$ and Jung-Su Chang 1,9,10,11,*(D)
}

\section{check for} updates

Citation: Faradina, A.; Tseng, S.-H.; Ho, D.K.N.; Nurwanti, E.; Hadi, H.; Purnamasari, S.D.; Rochmah, I.Y.; Chang, J.-S. Adherence to COVID-19 Nutrition Guidelines Is Associated with Better Nutritional Management Behaviors of Hospitalized COVID-19 Patients. Nutrients 2021, 13, 1918. https://doi.org/10.3390/nu13061918

Academic Editors: Zafeiria Mastora and Dimitrios T. Karayiannis

Received: 6 April 2021

Accepted: 31 May 2021

Published: 3 June 2021

Publisher's Note: MDPI stays neutra with regard to jurisdictional claims in published maps and institutional affiliations.

Copyright: (c) 2021 by the authors Licensee MDPI, Basel, Switzerland This article is an open access article distributed under the terms and conditions of the Creative Commons Attribution (CC BY) license (https:// creativecommons.org/licenses/by/ $4.0 /)$.
1 School of Nutrition and Health Sciences, College of Nutrition, Taipei Medical University, Taipei 110, Taiwan; amelia.faradinaa@gmail.com (A.F.); nganhdk91@gmail.com (D.K.N.H.)

2 Department of Physical Medicine and Rehabilitation, Taipei Medical University Hospital, Taipei 110, Taiwan; d301091012@tmu.edu.tw

3 Department of Physical Medicine and Rehabilitation, School of Medicine, College of Medicine, Taipei Medical University, Taipei 110, Taiwan

4 Department of Nutrition, Faculty of Health Sciences, University of Pembangunan Nasional Veteran, Jakarta 12450, Indonesia; estinurwanti@upnvj.ac.id

5 Department of Nutrition, Faculty of Health Sciences, Alma Ata University, Yogyakarta 55183, Indonesia; hhadi@almaata.ac.id (H.H.); sinthadewips@almaata.ac.id (S.D.P.)

6 Department of Public Health, Faculty of Health Sciences, Alma Ata University, Yogyakarta 55183, Indonesia

7 Alma Ata Center for Healthy Life and Foods (ACHEAF), Alma Ata University, Yogyakarta 55183, Indonesia

8 Nutrition Department, Hermina Tangkubanprahu Hospital, Malang 651194, Indonesia; rochmah.imaning@gmail.com

9 Graduate Institute of Metabolism and Obesity Sciences, College of Nutrition, Taipei Medical University, Taipei 110, Taiwan

10 Nutrition Research Center, Taipei Medical University Hospital, Taipei 110, Taiwan

11 Chinese Taipei Society for the Study of Obesity (CTSSO), Taipei 110, Taiwan

* Correspondence: susanchang@tmu.edu.tw; Tel.: +886-(2)-27361661 (ext. 6542); Fax: +886-(2)-2737-3112

Abstract: Good nutritional support is crucial for the immune system to fight against coronavirus disease 2019 (COVID-19). However, in the context of a pandemic with a highly transmissible coronavirus, implementation of nutrition practice may be difficult. A multicenter electronic survey involving 62 dieticians was conducted, in order to understand barriers associated with dieticians' adherence to nutrition guidelines for hospitalized COVID-19 patients in Indonesia. $69 \%$ of dieticians felt under stress when performing nutrition care, and $90 \%$ took supplements to boost their own immunity against the coronavirus. The concerns related to clinical practice included a lack of clear guidelines (74\%), a lack of access to medical records (55\%), inadequate experience or knowledge $(48 \%)$, and a lack of self-efficacy/confidence (29\%) in performing nutritional care. Half $(52 \%)$ of the dieticians had performed nutrition education/counseling, 47\% had monitored a patient's body weight, and $76 \%$ had monitored a patient's dietary intake. An adjusted linear regression showed that guideline adherence independently predicted the dieticians' nutrition care behaviors of nutrition counselling ( $\$: 0.24(0.002,0.08) ; p=0.04)$, and monitoring of body weight ( $\$$ : $0.43(0.04,0.11)$; $p=0.001)$ and dietary intake ( $(\mathrm{B}: 0.47(0.03,0.10) ; p=0.001)$ of COVID-19 patients. Overall, adherence to COVID-19 nutrition guidelines is associated with better nutritional management behaviors in hospitalized COVID-19 patients.

Keywords: COVID-19; nutrition care; guidelines adherence; length of stay; mortality; Indonesia

\section{Introduction}

Indonesia is among the 20 countries currently most severely affected by coronavirus disease 2019 (COVID-19) worldwide, with the fifth highest observed case-fatality ratio (3.0\% per 100 confirmed cases) [1]. The clinical characteristics of COVID-19 are diverse, 
and symptoms range from asymptomatic, mild with nonspecific symptoms (e.g., fever, cough, sore throat, and headaches), moderate/severe pneumonia with acute respiratory distress syndrome (ARDS) demanding mechanical ventilation, and multi-organ failure to death [2]. Currently, remdesivir is the only antiviral drug approved by the U.S. Food and Drug Administration (FDA) for treating COVID-19. Since there are limited effective antiviral drugs, supportive care with good nutritional support is crucial for the immune system to fight against coronavirus infection in hospitalized COVID-19 patients [2-5].

Dieticians are an integral part of healthcare systems, and are responsible for assessing the nutritional needs of hospitalized COVID-19 patients. However, one of the practical challenges of nutritional management with COVID-19 is the lack of clear guidelines, as the emerging coronavirus and its impacts on health are constantly evolving [2-5]. Although nutritional management of COVID-19 disease is, in principle, similar to that of hospitalized patients or patients in intensive care units (ICUs) [6], implementation of nutrition guidelines into clinical practice is a great challenge in the context of this pandemic with the highly transmissible coronavirus [7]. For example, dieticians might not be allowed to meet patients or perform nutritional assessments due to the risk of contracting or transmitting COVID-19. Frequently, some instruments for evaluating nutritional status are not readily available in most settings dedicated to COVID-19 patients. Indeed, dieticians should rely on rapid/alternative measures [8]. With the ongoing pandemic, health workers are burned out and are suffering from psychological symptoms (e.g., depression, anxiety, and insomnia), and these may also affect their motivation to implement nutrition guidelines $[9,10]$. Currently, little is known about the challenges and barriers that affect dieticians' implementation of COVID-19 nutritional guidelines. The broad aim of this study was to investigate barriers to dieticians' adherence to nutritional guidelines in hospitalized COVID-19 patients in Indonesia. Specific aims were: (1) to understand the practical challenges and concerns associated with nutritional care, and (2) to understand barriers (guideline knowledge, attitudes, and environmental factors) associated with nutritional management behaviors of dieticians (as indicated by monitoring a patient's body weight (BW) and dietary intake, as well as performing nutrition counseling/education).

\section{Materials and Methods}

\subsection{Study Participants}

This study was a multicenter electronic survey designed to understand the barriers associated with dieticians' adherence to clinical practice of nutrition care for hospitalized COVID-19 patients in Indonesia. This study was conducted during November 2020 January 2021. The link of the questionnaire (as a Google Form) was sent to social media groups of Indonesian dietetic association networks, where an estimated number of 210 of the group members were working as dieticians in a hospital. In total, 62 dieticians from 44 hospitals completed the online questionnaire, giving a response rate of $29.5 \%$. Out of the 44 participating hospitals, $39(88.6 \%)$ were located in Jakarta and Java Island, and had higher COVID-19 cases compared to other regions in Indonesia. In addition, 20 participating hospitals (45\%) were hospitals designated for COVID-19 by the Indonesia Ministry of Health. The study was conducted anonymously, and no personal data were collected (e.g., name or contact address). Participants were informed of the purpose of the online survey, and their consent to participate in the study was assumed if they completed the online survey. Each participant was allowed to complete the online survey only once. Participants were included if they were of Indonesian nationality, were employed as a dietician in a hospital, had performed nutritional care for hospitalized COVID-19 patients, and completed the online surveys. Exclusion criteria were a non-Indonesian nationality, dieticians who never performed nutritional care for hospitalized COVID-19 patients, and those who did not complete the online survey questionnaires. The study was approved by the Research Ethic Committee of Alma Alta University, Indonesia (KE/AA/XI/10323/EC/2020). 


\subsection{Survey Questionnaire: Barriers to Dietician Adherence to Nutrition Care for Hospitalized COVID-19 Patients}

The questionnaire was developed based on the framework of "barriers to physician adherence to practice guidelines in relation to behavior change", which was proposed by Cabana et al. and published in the Journal of the American Medical Association (JAMA) in 1999 [11]. The questionnaire consisted of four domains: knowledge (12 questions), attitudes (six questions), environmental factors (seven questions), and behaviors (three questions) (Supplementary Table S1). Depending on a participant's answers, each question was awarded 1 or 0 points, with a maximum of 28 points in total (Supplementary Table S1). For example, 1 point was awarded to a participant if they know "ESPEN guidelines on clinical nutrition in the intensive care unit" [6] or if they had "monitored the body weight of hospitalized COVID-19 patients". A higher total score of guideline knowledge, attitudes, environment, and behavior indicates better dietician adherence to clinical nutrition practices for hospitalized COVID-19 patients.

The "guideline knowledge section" (12 questions in total) included awareness of the guidelines (four questions) and familiarity with clinical nutrition practice of the guidelines (eight questions). The four guidelines were published between February 2019 and July 2020, and included the Coronavirus Disease 2019 (COVID-19) Treatment Guidelines (National Institutes of Health, USA) [2], ESPEN guidelines on clinical nutrition care in the intensive care unit (ICU) [6], ESPEN expert statements and practical guidance for nutritional management of individuals with SARS-CoV-2-infection [3], and Nutrition Therapy in the Patient with COVID-19 Disease Requiring ICU Care (reviewed and approved by the Society of Critical Care Medicine and the American Society for Parenteral and Enteral Nutrition) [5]. Familiarity with clinical practice associated with the guidelines included questions such as "is it important to conduct nutritional screening and nutritional assessment for hospitalized COVID-19 patients?" and "must the nutritional assessment and early nutritional care management of COVID-19 patients be integrated into the overall therapeutic strategy?" Respondents answered with "agree" or "disagree".

The "attitude section" (six question in total) consisted of two parts: self-efficacy or confidence (three questions) and motivation (three questions) in performing nutritional care for hospitalized COVID-19 patients. Examples of the statements included: "lack of selfefficacy or confidence in performing nutrition care for hospitalized COVID-19 patients?", and "feel stress when performing nutrition care for hospitalized COVID-19 patients?" Respondents answered with "agree" or "disagree". "Environmental factors" included seven questions including "lack of time, lack of resources, limited budget, limited food supply, lack of access to meet hospitalized COVID-19 patients, lack of access to medical records, and inadequate authority to perform nutritional care for hospitalized COVID-19 patients". "Dieticians' behavior" mainly focused on three nutrition care behaviors: (1) "Do you give nutrition education/counseling to hospitalized COVID-19 patients? If yes, how do you give nutrition education/counseling: educational video, educational leaflet, phone call, or text message?"; (2) “Do you monitor COVID-19 patient's body weight change? If yes, who monitors body weight and how do you do it?"; and (3) "Do you monitor dietary intake of hospitalized COVID-19 patients? If yes, who monitors it and how do you do it?" Total guidelines adherence score (maximum 28 points) was defined as knowledge (12 points), attitudes (six points), environmental factors (seven points), and dieticians' nutrition practice behaviors (three points). A high total score indicated a better adherence to nutrition guidelines for hospitalized COVID-19 patients.

\subsection{Primary Outcome}

The primary outcomes were dieticians' behaviors of nutrition care and self-efficacy or confidence in providing nutrition care for hospitalized COVID-19 patients. The dieticians' behaviors of nutrition care included: (1) conducting nutrition counseling/education, (2) monitoring patients' weight changes, and (3) monitoring patients' dietary intake. 


\subsection{Data Analysis}

Statistical analyses were conducted using SPSS 19 (IBM, Armonk, NY, USA). Continuous data are presented as the mean and standard deviation (SD), and categorical data are presented as the number $(n)$ and percentage (\%). Differences between two groups were analyzed by an unpaired $t$-test. Chi-squared or Fisher's exact test was employed to compare proportions. An age, gender, years of practice, and type of hospital-adjusted multivariate linear regression model was employed to examine relationships between dependent variables (dieticians' nutrition practice behaviors) and potential variables related to guideline adherence (total adherence score and its individual components: knowledge, attitude, and environmental factors). $p<0.05$ was considered statistically significant.

\section{Results}

\subsection{Participant Characteristics}

Table 1 shows baseline characteristics of study participants. In total, 62 Indonesian dieticians participated in the survey; $89 \%$ were female and $56 \%$ had $\leq 5$ years of clinical experience. Most participants worked in hospitals located in Jakarta (40\%), East Java (21\%), and Central Java (16\%). All participants $(100 \%)$ had experience in performing nutritional therapy for hospitalized COVID-19 patients, with $48 \%$ conducting nutritional therapy for severely and critically ill patients, $40 \%$ for patients with mild and moderate illness, and $12 \%$ for asymptomatic patients. However, $69 \%$ of dieticians felt stress when performing nutritional therapy for hospitalized COVID-19 patients. Ninety percent of participants took supplements or herbal remedies to boost their own immunity against COVID-19, with 63\% taking vitamin C, $45 \%$ taking vitamin B complex, 30\% taking multivitamins and minerals, and $25 \%$ consuming ginger (Table 1 ).

\subsection{Concerns Related to Nutritional Practices of COVID-19}

Table 2 shows concerns related to clinical practices of nutrition care of COVID-19 patients. The most commonly used nutritional screening tools were malnutrition universal screening tools (MUST) (34\%) and malnutrition screening tools (MST) (34\%), and nutrition assessments were mainly performed by nurses $(58 \%)$ and dieticians $(40 \%)$ (Table 2$)$. Seventy-six percent of participants had monitored a patient's dietary intake; however, only half had monitored a patient's weight change $(47 \%)$ or had provided nutrition education or counseling (52\%). Ninety-seven percent of participants had recommended supplements for hospitalized COVID-19 patients, of which vitamin C (61\%), vitamin B complex (60\%), multivitamins /minerals (48\%), zinc ( $40 \%$ ), and omega 3 fatty acids ( $27 \%$ ) were the most frequently recommended supplements. Sixty-eight percent of participants had experience in designing individual diets for hospitalized COVID-19 patients, with $68 \%$ modifying the protein content and $63 \%$ modifying the total energy. Concerns related to nutritional practices of hospitalized COVID-19 patients included a lack of clear guidelines $(74 \%)$, a lack of access to meet COVID-19 patients (55\%), inadequate experience or knowledge (48\%), a lack of self-efficacy or confidence in performing nutrition care $(29 \%)$, a lack of resources $(29 \%)$, a limited food supply (29\%), and a limited budget (26\%) (Table 2).

\subsection{Barriers to Dieticians' Adherence to Nutrition Guidelines for COVID-19}

Next, we evaluated barriers to dieticians' adherence to clinical guidelines (Table 3). More than half of the dieticians were aware of "COVID-19 treatment guidelines" (total: $65 \%$; among those with $>5$ years of experience: $74 \%$; and among those with $\leq 5$ years of experience: $57 \%$ ) and "ESPEN guideline on clinical nutrition in the intensive care unit" (total: $58 \%$; among those with $>5$ years of experience: $48 \%$; and among those with $\leq 5$ years of experience: $66 \%$ ), but to a lesser extent, "nutrition therapy in the patient with COVID-19 disease requiring ICU care" (total: 35\%; among those with $>5$ years of experience: $37 \%$; and among those with $\leq 5$ years of experience: $34 \%$ ), and "ESPEN expert statements and practical guidance for nutritional management of individuals with SARS-CoV-2 infection" (total: $24 \%$; among those with $>5$ years of experience: $26 \%$; and among those with $\leq 5$ years 
of experience: $23 \%$ ). Most participants were familiar with knowledge of nutrition practice $(95-100 \%)$ (Table 3). However, $74 \%$ of participants thought that there was a lack of clear guidelines for COVID-19, and this rate was slightly higher among junior dieticians (those with $\leq 5$ years of experience: $83 \%$ ) than senior (those with $>5$ years of experience: $63 \%$ ) $(p=0.076)$ (Table 3: Knowledge: Familiarity with clinical practice). Junior dieticians also had lower agreement rates on questions of "I am knowledgeable about the role of nutrition therapy for hospitalized COVID-19 patients" (junior: $43 \%$ vs. senior: $81 \%, p=0.004$ ) and "self-efficacy or confidence in performing nutrition care for hospitalized COVID-19 patients" (junior: $57 \%$ vs. senior: $89 \%, p=0.006$ ), but had a higher rate of "feeling stress when performing nutrition care for hospitalized COVID-19 patients" (junior: $83 \%$ vs. senior: $52 \%$, $p=0.009$ ). Although $95 \%$ of participants agreed that "nutrition counseling is important for hospitalized COVID-19 patients" (Table 3: Knowledge: Familiarity of the guidelines), only half of dieticians (total: $52 \%$ ) had conducted nutrition education/counseling for hospitalized COVID-19 patients, and this rate was much higher among junior dieticians (junior: $71 \%$ vs. senior: $26 \%$; $p<0.0001$ ). Only $47 \%$ (junior: $54 \%$ vs. senior: $37 \%, p=0.177$ ) had monitored BW changes and $76 \%$ (junior: $74 \%$ vs. senior: $78 \%$ ) had monitored dietary intake of hospitalized COVID-19 patients (Table 3: Behavior)

Table 1. Characteristics of the study participants $(N=62)$.

\begin{tabular}{|c|c|}
\hline Characteristic & Responses \\
\hline \multicolumn{2}{|l|}{ Hospital Characteristic } \\
\hline \multicolumn{2}{|l|}{ Type of hospital $(n, \%)$} \\
\hline Government hospital & $23(52 \%)$ \\
\hline Private hospital & $21(48 \%)$ \\
\hline \multicolumn{2}{|l|}{ Region of hospital $(n, \%)$} \\
\hline Yogyakarta and Central Java & $10(23 \%)$ \\
\hline East Java & $11(25 \%)$ \\
\hline Jakarta & $12(27 \%)$ \\
\hline West Java & $5(11 \%)$ \\
\hline Bali and others & $6(14 \%)$ \\
\hline Number of hospitalized COVID-19 patients & $14,898.69 \pm 23,441.78$ \\
\hline Mortality rate (n, ratio) & $1186(0.02)$ \\
\hline Average length of stay of COVID-19 patients (day) & $19.58 \pm 1.61$ \\
\hline Asymptomatic & $\mathrm{N} / \mathrm{A}$ \\
\hline Mild Illness & $12.58 \pm 1.61$ \\
\hline Moderate Illness & $16.04 \pm 1.55$ \\
\hline Severe Illness & $21.50 \pm 2.13$ \\
\hline Critical Illness & $27.54 \pm 2.64$ \\
\hline \multicolumn{2}{|l|}{ Dieticians' characteristics } \\
\hline Age (years) & $29.27 \pm 6.10$ \\
\hline Female $(n, \%)$ & $55(89 \%)$ \\
\hline \multicolumn{2}{|l|}{ Years of practice } \\
\hline$<1$ year & $16(26 \%)$ \\
\hline $1 \sim 5$ years & $19(31 \%)$ \\
\hline $5 \sim 10$ years & $14(23 \%)$ \\
\hline$>10$ years & $13(21 \%)$ \\
\hline Have you ever performed nutrition therapy for COVID-19 patients? (yes) & $62(100 \%)$ \\
\hline \multicolumn{2}{|l|}{ Stages of COVID-19 patients treated? $(n, \%)$} \\
\hline Asymptomatic & $4(6 \%)$ \\
\hline Mild and moderate illness & $20(32 \%)$ \\
\hline Severe and critical illness & $38(61 \%)$ \\
\hline Feel stress when performing nutritional therapy for COVID-19 patients? & $43(69 \%)$ \\
\hline Take supplements to boost your own immunity against COVID-19? & $56(90 \%)$ \\
\hline B complex & $25(45 \%)$ \\
\hline Vitamin C & $35(63 \%)$ \\
\hline Multivitamins and minerals & $17(30 \%)$ \\
\hline Ginger & $14(25 \%)$ \\
\hline
\end{tabular}

Continuous variables are presented as the mean \pm standard deviation (SD), and categorical data as the number (n) (percentage). Mortality rate (case fatality rate) was defined as the number of deaths divided by the number of confirmed cases. 
Table 2. Nutrition practice and concerns related to hospitalized COVID-19 patients $(N=62)$.

\begin{tabular}{|c|c|}
\hline Nutritional Practice & Responses \\
\hline \multicolumn{2}{|l|}{ Nutritional screening tools used? } \\
\hline Nutrition Risk Screening-2002 (NRS-2002) & $7(11 \%)$ \\
\hline Mini Nutritional Assessment (MNA) & $12(19 \%)$ \\
\hline Malnutrition Universal Screening Tools (MUST) & $21(34 \%)$ \\
\hline Subjective Global Assessment (SGA) & $4(6 \%)$ \\
\hline Malnutrition Screening Tools (MST) & $21(34 \%)$ \\
\hline \multicolumn{2}{|l|}{ Who performs nutritional screening for COVID-19 patients? } \\
\hline Dietitian & $25(40 \%)$ \\
\hline Doctor & $1(2 \%)$ \\
\hline Nurse & $36(58 \%)$ \\
\hline Monitor weight change in COVID-19 patients? (yes: $n, \%$ ) & $29(47 \%)$ \\
\hline \multicolumn{2}{|l|}{ If yes, who monitors it? } \\
\hline Dietitian & $21(34 \%)$ \\
\hline Nurse & $6(20 \%)$ \\
\hline Self-reported by patient & $2(3 \%)$ \\
\hline Monitor dietary intake of COVID-19 patients? (yes: $n, \%$ ) & $47(76 \%)$ \\
\hline \multicolumn{2}{|l|}{ If yes, who monitors it? } \\
\hline Dietitian & $28(35 \%)$ \\
\hline Nurse & $13(27 \%)$ \\
\hline Health care & $4(8 \%)$ \\
\hline Reported by patient & $6(10 \%)$ \\
\hline Performed nutritional counseling for COVID-19 patients? (yes: $n, \%$ ) & $32(52 \%)$ \\
\hline \multicolumn{2}{|l|}{ If yes, how do you do it? } \\
\hline Educational leaflet & $8(13 \%)$ \\
\hline Phone call & $19(31 \%)$ \\
\hline Text message & $10(16 \%)$ \\
\hline Meet the patient in person & $4(6 \%)$ \\
\hline Video call & $1(2 \%)$ \\
\hline Give education to the family & $1(2 \%)$ \\
\hline Recommend supplements for COVID-19 patients? (yes: $n, \%$ ) & $60(97 \%)$ \\
\hline B complex & $37(60 \%)$ \\
\hline Vitamin C & $38(61 \%)$ \\
\hline Multivitamins and minerals & $30(48 \%)$ \\
\hline Zinc & $25(40 \%)$ \\
\hline Omega-3 fatty acids & $17(27 \%)$ \\
\hline Designed individual diets for hospitalized COVID-19 patients? (yes: $n, \%$ ) & $42(68 \%)$ \\
\hline Modify total energy & $39(63 \%)$ \\
\hline Modify carbohydrate content & $15(24 \%)$ \\
\hline Modify protein content & $42(68 \%)$ \\
\hline Modify lipid content & $10(16 \%)$ \\
\hline Modify fruits and vegetables & $20(32 \%)$ \\
\hline Give supplements & $13(21 \%)$ \\
\hline No differences & $7(11 \%)$ \\
\hline $\begin{array}{l}\text { Confidence in performing nutritional support for COVID-19 patients } \\
\text { with poly-comorbidities (5: very confident; 3: slightly confident; } 1 \text { : } \\
\text { not confident) }\end{array}$ & $3.37 \pm 0.96$ \\
\hline
\end{tabular}
not confident)

Concerns related to nutrition care for COVID-19 patients

$\begin{array}{lc}\text { Lack of clear guidelines } & 46(74 \%) \\ \text { Lack of self-efficacy or confidence in performing nutritional care } & 18(29 \%) \\ \text { Inadequate experience or knowledge } & 30(48 \%) \\ \text { Limited budget } & 16(26 \%) \\ \text { Lack of time } & 7(11 \%) \\ \text { Lack of resources } & 18(29 \%) \\ \text { Limited food supply } & 18(29 \%) \\ \text { Lack of access to meet COVID-19 patients } & 34(55 \%) \\ \text { Lack of access to medical records } & 9(15 \%)\end{array}$

Continuous variables are presented as the mean \pm standard deviation (SD). Categorical variables are presented as number $(n)$ (percentage). 
Table 3. Barriers to dietician adherence to nutritional guidelines in relation to nutritional practice behaviors of hospitalized COVID-19 patients.

\begin{tabular}{|c|c|c|c|c|}
\hline \multirow{2}{*}{ Barriers } & \multirow{2}{*}{$\begin{array}{c}\text { Total } \\
(N=62)\end{array}$} & \multicolumn{2}{|c|}{ Years of Practice } & \multirow{2}{*}{$p$ Value * } \\
\hline & & $\leq 5$ Years $(N=35)$ & $>5$ Years $(N=27)$ & \\
\hline \multicolumn{5}{|c|}{ Knowledge } \\
\hline \multicolumn{5}{|l|}{ Awareness of guidelines } \\
\hline ESPEN guidelines on clinical nutrition in the intensive care unit [6] & $36(58 \%)$ & $23(66 \%)$ & $13(48 \%)$ & 0.165 \\
\hline $\begin{array}{l}\text { ESPEN expert statements and practical guidance for nutritional } \\
\text { management of individuals with SARS-CoV-2-infection (Europe) [3] } \\
\text { Nutrition Therapy in Patients with COVID-19 Disease Requiring ICU }\end{array}$ & $15(24 \%)$ & $8(23 \%)$ & $7(26 \%)$ & 0.780 \\
\hline $\begin{array}{l}\text { Care (reviewed and approved by the Society of Critical Care Medicine } \\
\text { and the American Society for Parenteral and Enteral Nutrition) [5] }\end{array}$ & $22(35 \%)$ & $12(34 \%)$ & $10(37 \%)$ & 0.822 \\
\hline $\begin{array}{l}\text { Coronavirus Disease } 2019 \text { (COVID-19) Treatment Guidelines (National } \\
\text { Institutes of Health, USA) [2] }\end{array}$ & $40(65 \%)$ & $20(57 \%)$ & $20(74 \%)$ & 0.167 \\
\hline \multicolumn{5}{|l|}{ Familiarity with the guidelines } \\
\hline $\begin{array}{l}\text { The nutritional assessment and early nutritional care management } \\
\text { of COVID-19 patients must be integrated into the overall } \\
\text { therapeutic strategy }\end{array}$ & $62(100 \%)$ & $35(100 \%)$ & $27(100 \%)$ & NA \\
\hline $\begin{array}{l}\text { It is important to conduct nutritional screening and nutritional } \\
\text { assessment of hospitalized Covid-19 patients }\end{array}$ & $61(98 \%)$ & $34(97 \%)$ & $27(100 \%)$ & 0.376 \\
\hline $\begin{array}{l}\text { It is important to monitor the body weight change in hospitalized } \\
\text { COVID-19 patients }\end{array}$ & $48(77 \%)$ & $27(77 \%)$ & $21(78 \%)$ & 0.953 \\
\hline $\begin{array}{l}\text { It is important to monitor the dietary intake of hospitalized } \\
\text { COVID-19 patients }\end{array}$ & $62(100 \%)$ & $35(100 \%)$ & $27(100 \%)$ & NA \\
\hline $\begin{array}{l}\text { Nutrition therapy plays an important role in the outcomes of } \\
\text { COVID-19 treatment }\end{array}$ & $62(100 \%)$ & $35(100 \%)$ & $27(100 \%)$ & NA \\
\hline Nutrition supplementation is useful for treating COVID-19 patients & $60(97 \%)$ & $33(94 \%)$ & $27(100 \%)$ & 0.207 \\
\hline Nutrition counseling is important for COVID-19 patients & $59(95 \%)$ & $32(91 \%)$ & $27(100 \%)$ & 0.119 \\
\hline Lack of clear guidelines & $46(74 \%)$ & $29(83 \%)$ & $17(63 \%)$ & 0.076 \\
\hline \multicolumn{5}{|c|}{ Attitudes } \\
\hline \multicolumn{5}{|l|}{ Self-efficacy/confidence in performing nutritional care } \\
\hline $\begin{array}{l}\text { I am knowledgeable about the role of nutrition therapy for } \\
\text { COVID-19 patients }\end{array}$ & $37(60 \%)$ & $15(43 \%)$ & $22(81 \%)$ & 0.004 \\
\hline $\begin{array}{l}\text { Self-efficacy or confidence in performing nutrition care for } \\
\text { hospitalized COVID-19 patients }\end{array}$ & $44(71 \%)$ & $20(45 \%)$ & $24(89 \%)$ & 0.006 \\
\hline $\begin{array}{l}\text { I have adequate knowledge to design meals for hospitalized } \\
\text { COVID-19 patients }\end{array}$ & $32(52 \%)$ & $16(50 \%)$ & $16(50 \%)$ & 0.290 \\
\hline \multicolumn{5}{|l|}{ Motivation in performing nutritional care } \\
\hline $\begin{array}{l}\text { I regularly make decisions regarding nutrition therapy as part of the } \\
\text { management of COVID-19 patients }\end{array}$ & $50(81 \%)$ & $28(80 \%)$ & $22(81 \%)$ & 0.884 \\
\hline $\begin{array}{l}\text { I have an obligation to improve the health of COVID-19 patients by } \\
\text { discussing nutrition with them }\end{array}$ & $59(95 \%)$ & $33(94 \%)$ & $26(96 \%)$ & 0.715 \\
\hline $\begin{array}{l}\text { I feel stress when performing nutrition care for hospitalized } \\
\text { COVID-19 patients }\end{array}$ & $43(69 \%)$ & $29(83 \%)$ & $14(52 \%)$ & 0.009 \\
\hline \multicolumn{5}{|c|}{ Environmental factors } \\
\hline Lack of time & $7(11 \%)$ & $4(11 \%)$ & $3(11 \%)$ & 0.969 \\
\hline Lack of resources & $18(29 \%)$ & $11(31 \%)$ & $7(26 \%)$ & 0.636 \\
\hline Limited budget & $16(26 \%)$ & $8(23 \%)$ & $8(30 \%)$ & 0.546 \\
\hline Limited food supplies & $18(29 \%)$ & $13(37 \%)$ & $5(19 \%)$ & 0.109 \\
\hline Lack of access to meet hospitalized COVID-19 patients & $34(55 \%)$ & $16(46 \%)$ & $18(67 \%)$ & 0.100 \\
\hline Lack of access to medical records & $9(15 \%)$ & $4(11 \%)$ & $5(19 \%)$ & 0.432 \\
\hline $\begin{array}{l}\text { Inadequate authority to perform nutritional care for hospitalized } \\
\text { COVID-19 patients }\end{array}$ & $4(6 \%)$ & $3(9 \%)$ & $1(4 \%)$ & 0.439 \\
\hline \multicolumn{5}{|c|}{ Nutritional practice behaviors } \\
\hline $\begin{array}{l}\text { Perform nutrition education or counseling for hospitalized COVID-19 } \\
\text { patients }\end{array}$ & $32(52 \%)$ & $25(71 \%)$ & $7(26 \%)$ & $<0.0001$ \\
\hline Monitor body weight of hospitalized COVID-19 patients & $29(47 \%)$ & $19(54 \%)$ & $10(37 \%)$ & 0.177 \\
\hline Monitor dietary intake of hospitalized COVID-19 patients & $47(76 \%)$ & $26(74 \%)$ & $21(78 \%)$ & 0.502 \\
\hline
\end{tabular}

All variables are expressed as the number $(n)$, percentage $(\%) .{ }^{*}$ The $p$ value was analyzed using unpaired Student's $t$-test for continuous variables or Chi-squared test for categorical variables. 


\subsection{Factors Predicting Nutrition Care Behaviors of COVID-19 Patients \\ 3.4.1. Self-Efficacy or Confidence in Providing Nutrition Care}

Next, we performed a multivariate linear regression analysis to identify factors associated with behaviors of nutrition care for hospitalized COVID-19 patients (Table 4). Age, gender and years of practice-adjusted regression showed that nutrition guideline adherence score ( $B:-0.25(-0.07,-0.01) ; p=0.03)$ was negatively correlated with lack of self-efficacy, and, to a lesser extent, disease severity ( $B: 0.22(-0.01,0.33) ; p=0.057)$ (Table 4).

Table 4. Adjusted multivariate regression coefficient (ß) and 95\% confidence intervals (CIs) of barriers of nutrition practice behaviors of COVID-19 patients.

\begin{tabular}{|c|c|c|c|c|c|c|c|c|}
\hline Variables & $\begin{array}{c}\text { Lack of } \\
\text { Self-Efficacy * }\end{array}$ & $p$-Value & $\begin{array}{l}\text { Nutrition } \\
\text { Counseling * }\end{array}$ & $p$-Value & $\begin{array}{l}\text { Monitor Body } \\
\text { Weight * }\end{array}$ & $p$-Value & $\begin{array}{l}\text { Monitor Dietary } \\
\text { Intake }\end{array}$ & $p$-Value \\
\hline Disease severity & $0.22(-0.01,0.33)$ & 0.057 & $0.24(-0.02,0.41)$ & 0.077 & $0.05(-0.17,0.25)$ & 0.690 & $0.15(-0.09,0.28)$ & 0.286 \\
\hline Type of hospital & $-0.07(-0.29,0.15)$ & 0.527 & $0.05(-0.20,0.30)$ & 0.674 & $0.03(-0.29,0.24)$ & 0.844 & $0.11(-0.32,0.14)$ & 0.435 \\
\hline Total adherence score & $-0.25(-0.07,-0.01)$ & 0.030 & $0.24(0.01,0.08)$ & 0.040 & $0.43(0.04,0.11)$ & 0.001 & $0.47(0.03,0.10)$ & 0.001 \\
\hline Knowledge (total score) & $-0.15(-0.12,0.03)$ & 0.209 & $0.19(-0.03,0.15)$ & 0.157 & $0.13(-0.04,0.13)$ & 0.287 & $0.05(-0.06,0.09)$ & 0.708 \\
\hline Guideline awareness & $-0.01(-0.08,0.08)$ & 0.969 & $0.70(0.18,0.31)$ & $<0.0001$ & $0.15(-0.04,0.15)$ & 0.273 & $0.35(0.03,0.19)$ & 0.010 \\
\hline Guideline Familiarity & $-0.05(-0.22,0.14)$ & 0.666 & $0.11(0.13,0.33)$ & 0.402 & $0.01(-0.19,0.18)$ & 0.936 & $0.03(-0.22,0.17)$ & 0.173 \\
\hline Attitude (total score) & NA & & $0.07(-0.08,0.14)$ & 0.584 & $0.15(-0.30,0.13)$ & 0.210 & $0.03(0.02,0.15)$ & 0.012 \\
\hline $\begin{array}{l}\text { Self-efficacy } \\
\text { or confidence }\end{array}$ & NA & & $0.05(-0.45,0.03)$ & 0.660 & $0.08(-0.10,0.19)$ & 0.643 & $0.31(0.03,0.26)$ & 0.013 \\
\hline Motivation & $-0.18(-0.04,0.35)$ & 0.112 & $0.03(-0.26,0.20)$ & 0.800 & $0.07(-0.17,0.30)$ & 0.568 & $0.23(0.02,0.39)$ & 0.040 \\
\hline Feel stress & $0.23(-0.48,0.31)$ & 0.080 & $-0.37(-0.67,-0.12)$ & 0.006 & $-0.24(-0.57,0.04)$ & 0.091 & $-0.21(-0.46,0.08)$ & 0.172 \\
\hline $\begin{array}{l}\text { Environmental factor } \\
\text { (total score) }\end{array}$ & $-0.15(-0.15,0.03)$ & 0.186 & $0.08(-0.15,0.08)$ & 0.535 & $0.15(-0.04,0.18)$ & 0.217 & $0.12(-0.06,0.14)$ & 0.384 \\
\hline
\end{tabular}

Total adherence score (maximum 28 points) was defined as knowledge (12 questions), attitudes (six questions), environmental factors (seven questions), and behaviors (three questions). ${ }^{*}$ Results were adjusted for age, gender, years of practice, and type of hospital.

3.4.2. Nutrition Care Behaviors: Nutrition Counseling, and Monitoring of BW and Dietary Intake

A regression analysis adjusted for age, gender and years of practice showed that guideline adherence scores also independently predicted dieticians' nutrition care behaviors of nutrition counselling (B: $0.24(0.002,0.08) ; p=0.04)$, and monitoring of BW (B: 0.43 $(0.04,0.11) ; p=0.001)$ and dietary intake $(B: 0.47(0.03,0.10) ; p=0.001)$ of hospitalized COVID-19 patients (Table 4). Detail analysis of barriers to dieticians' adherence to nutrition guidelines found that awareness of guidelines was positively correlated with nutrition counselling ( $\$: 0.70(0.18,0.31) ; p<0.0001)$, and monitoring patient's dietary intake ( $\$: 0.35$ $(0.03,0.19) ; p=0.01)$. Those dieticians who had better attitude (total score) (1: $0.03(0.02$, $0.15) ; p=0.012)$, self-efficacy or confidence ( $B$ : $0.31(0.03,0.26) ; p=0.013)$ or motivation (B: $0.23(0.02,0.39) ; p=0.04)$ in performing nutrition care were more likely to monitor a patient's BW (Table 4: adjusted for age, gender, years of practice, and type of hospital).

Next, we investigated the relationship between dieticians' adherence to nutrition guidelines, length of stay and COVID-19 mortality. Adjusted linear regression analysis showed that guideline awareness was negatively correlated with the length of stay for moderate symptoms ( $\beta$ : $-0.51(-1.22,-0.14) ; p=0.017)$, severe symptoms ( $($ : -0.31 $(-1.48,-0.26) ; p=0.04)$ and critical illness (B: $-0.46(-1.45,-0.16) ; p=0.029)$, but not mild symptoms. Guideline familiarity also independently predicted COVID-19 mortality (ß: $-40.95(-63.95,-17.95) ; p=0.001)$ (Supplementary Table S2).

\section{Discussion}

Our study results indicated that adherence to COVID-19 nutrition guidelines is associated with better nutritional management and, possibly, related to clinical outcome. Studies showed that adherence to nutrition guidelines in critically ill patients is associated with better survival outcomes [12,13]. Currently, Indonesia is not only facing capacity constraints in the health care sector (e.g., man power, funding and facility) but also the unprecedented economic burden of the direct medical cost of COVID-19. It is estimated that median lengths of stay of hospitalized COVID-19 patients were $4 \sim 53$ days in China 
and 4 21 days outside of China [14]. In the United States, a single symptomatic COVID-19 infection would cost a direct medical cost of USD 3,045 and one hospitalized case would cost a median of USD 14,366, which only covers costs during the course of the infection and not the follow-up care [15]. The importance of appropriate nutritional assessments and treatments cannot be overstated. The health of COVID-19 patients may rapidly deteriorate after being hospitalized, and patients may develop progressive hypermetabolism 1 week after being intubated in the ICU, which may require 1.6 1.8-times higher energy inputs by the third week post-intubation [16]. Screening and monitoring of a patient's BW and dietary intake can help doctors and dieticians identify patients at risk of poor outcomes, and also allow planning of individualized nutrition care to support a patient's immune system in fighting the coronavirus [17]. This is of particular importance for COVID-19, since supportive care is the major treatment method for hospitalized COVID-19 patients, and most severe and critically ill COVID-19 patients are at risk of malnutrition [18,19].

Awareness of guidelines also predicts a dietician's adherence to nutrition guidelines for COVID-19. In the context of a constantly evolving and highly contagious coronavirus, implementation of nutrition guidelines might not be straightforward. Dieticians need to quickly adapt to a wide range of work environments and upgrade their nutrition care programs through training, self-study, or discussing practical problems in real-time through online social networks with fellow dieticians to provide optimal service to COVID-19 patients. Our study found that major concerns related to the nutrition care of COVID-19 patients were a lack of clear guidelines (74\%), a lack of self-efficacy $(29 \%)$, and inadequate experience or knowledge (48\%). Dissemination of COVID-19 guidelines with their management algorithm may improve dieticians' knowledge and promote adherence to guidelines. However, passive dissemination of guidelines might not be effective in the context of the ever-changing COVID-19 pandemic, as the guidelines need to be adapted to local healthcare environments. It is likely that active dissemination or targeted approaches together with supportive networks would improve awareness of, and adherence to, guidelines. For example, Canadian dieticians launched a "COVID-19 response group" on Facebook for dieticians and nutrition students to discuss nutrition care issues, share experiences, and seek advice. Online supportive networks may be particularly important for junior dieticians as our study showed that they had lower self-efficacy/confidence and knowledge than senior dieticians.

Currently, Indonesian hospitals are overwhelmed by COVID-19 and our study found that most Indonesia dieticians, in particularly junior dieticians, are suffering from psychological stress when performing nutritional care for hospitalized COVID-19 patients. Increased psychological stress among junior dieticians is likely due to the combination factors of a higher rate of performing nutritional counseling and a lack of self-efficacy/confidence in performing nutritional care for hospitalized COVID-19 patients. The current study found that psychological stress not only predicted dieticians' self-efficacy/confidence but also their behaviors of nutrition care of COVID-19. Lu and Dollahite showed that years of nutrition counselling experience significantly predicted self-efficacy scores [20]. Currently, we do not know why Indonesian junior dieticians had a higher rate of performing nutritional counseling for hospitalized COVID-19 patients than senior dieticians, despite the lack of clinical experience. Another interesting finding is that most of dieticians (90\%) took supplements as well as recommending supplements (Vitamins C and B complex, multivitamins and zinc) to COVID-19 patients, despite the fact that the COVID-19 Treatment Guidelines stated that there are insufficient data for the panel to recommend the use of vitamins or minerals for the treatment of COVID-19 [2]. Using Google Trends to analyze worldwide concerns with immune-boosting nutrients/herbs during the COVID-19 pandemic, our previous study found that vitamin C, D, E and zinc were the most searched nutrients during the first wave of COVID-19 pandemic [21]. Vitamins and minerals have anti-inflammatory and antioxidant properties, which may support a healthy immune system against coronavirus infection. However, the effects of vitamin and mineral supplementation on COVID-19 remain inconclusive [22,23]. It is very important to prevent 
or treat nutritional deficiencies. However, supplementation with a supraphysiologic or supratherapeutic amount of micronutrients has not been recommended in the prevention or improvement of clinical outcomes of COVID-19 infection. Therefore, the provision of daily allowances for vitamins and trace elements has been suggested [3,24].

Our study found that environmental factors such as a lack of access to meet COVID19 patients in person was not a barrier to nutrition care practice. To overcome physical barriers, Indonesian dieticians have employed telemedicine to perform nutrition counseling and monitor patients' food intake and weight changes. However, feeling stress when independently performing nutrition care predicts the behavior of monitoring a patient's BW. This suggests that, even when upgrading one's skills through telehealth channels, dieticians still suffer from psychological stress when dealing with COVID-19. Health organizations need to identify sources of stress and adapt their clinical practice to support nutrition care. Another barrier that predicts the behavior of monitoring a patient's food intake is the lack of access to medical records. Nutrition care might not be considered a priority in the COVID-19 pandemic, as acknowledged by Thibault and colleagues [7]. Based on their experiences with the COVID-19 pandemic in France, those authors emphasized the need to adapt protocols of nutrition care that are simple and easily applied [7]. Overall, our study results suggest that dieticians need to upgrade their skills in telemedicine and adapt to the local healthcare environment in order to strategize plans for performing individualized nutrition care during the ever-changing COVID-19 pandemic.

The strength of this study includes its novelty, as it is the first to investigate barriers affecting COVID-19 nutrition care, as well as being a multicenter survey with all participants having experience in nutrition care of hospitalized COVID-19 patients. The present study also has several limitations. Firstly, there was a relatively small sample size $(n=62)$ with only one country surveyed (Indonesia) and a low response rate (29.5\%). We recognized that a regional study with small sample size may not provide a complete picture of dietetic practice in Indonesia and other countries during the COVID-19 outbreak. The low response rate in our study is due, in part, to the exclusion of dieticians who never performed nutritional care for hospitalized COVID-19 patients in Indonesia. The COVID-19 outbreak itself may also contribute to the low response rate. A recent study in UK also found a limited number of dietitians was able to participate in the online survey due to COVID-19 outbreak, though no response rate was reported [25]. Secondly, information was collected online and not through face-to face interviews. Limitations of online surveys have been noted and intensively discussed [26]. The major strengths of the online survey were its cost effectiveness and the ability to be conducted in a short period of time with no regional restrictions; however, there were concerns about internet accessibility, a lack of control of the sampling or response rate, and ethical issues (e.g., consent, anonymity, and confidentiality) [26]. Nonetheless, it was performed in the context of social distancing during the COVID-19 pandemic, and consent was obtained through participation in the online survey, and all responses were anonymous; the research ethics committee in Indonesia approved the current study. Other limitations include the fact that more confounding factors are needed for the linear regression model when analyzing the relationship between the predictive effect of dieticians' adherence to nutrition guidelines and the clinical outcomes (survival and length of stay).

\section{Conclusions}

Our study results indicate that adherence to COVID-19 nutrition guidelines is associated with better nutritional management and, possibly, better clinical outcomes. A further validation study is needed in order to provide some definitive guidance on how to implement nutrition guidelines, as well as how the adherence to COVID-19 nutrition guidelines may affect medical cost and economy during the ever-changing COVID-19 pandemic.

Supplementary Materials: The following are available online at https:/ /www.mdpi.com/article/10 .3390/nu13061918/s1, Supplementary Table S1: Barriers to dietician adherence to clinical practice of nutrition guidelines for hospitalized COVID-19 patients. Supplementary Table S2: Adjusted 
multivariate regression coefficient $(\beta)$ and $95 \%$ Confidence Intervals (95\% CI) for length of stay and mortality of hospitalized COVID-19 patients in Indonesia.

Author Contributions: A.F., D.K.N.H., S.-H.T., H.H. and J.-S.C. designed the study and conducted the initial searches. A.F., E.N., S.D.P. and I.Y.R. contributed to recruitment of dieticians. Data were analyzed by A.F. and J.-S.C. drafted the paper. All authors have read and agreed to the published version of the manuscript.

Funding: Jung-Su Chang was supported by grants from Taipei Medical University Hospital (110TMUTMUH-09) and the Ministry of Science and Technology, Taiwan (MOST 107-2320-B-038-010-MY3 and MOST 109-2923-B-038-001-MY3).

Institutional Review Board Statement: The study was approved by the Research Ethic Committee of Alma Alta University, Indonesia (KE/AA/XI/10323/EC/2020).

Informed Consent Statement: Informed consent was obtained from all subjects involved in the study.

Data Availability Statement: The data are not publicly available due to participant confidentiality.

Acknowledgments: We thank all Indonesian dieticians who participated in the survey.

Conflicts of Interest: The authors declare that no competing interest exists.

\section{References}

1. John Hopkins University and Medicine Coronavirus Resource Center. Mortality in the Most Affected Countries. Available online: https:/ / coronavirus.jhu.edu/data/mortality (accessed on 5 January 2021).

2. National Institutes of Health USA. COVID-19 Treatment Guidelines Panel. Coronavirus Disease 2019 (COVID-19) Treatment Guidelines. National Institutes of Health. Available online: https://www.covid19treatmentguidelines.nih.gov/ (accessed on 4 January 2021).

3. Barazzoni, R.; Bischoff, S.C.; Breda, J.; Wickramasinghe, K.; Krznaric, Z.; Nitzan, D.; Pirlich, M.; Singer, P. Espen expert statements and practical guidance for nutritional management of individuals with sars-cov-2 infection. Clin. Nutr. 2020, 39, 1631-1638. [CrossRef]

4. Thibault, R.; Seguin, P.; Tamion, F.; Pichard, C.; Singer, P. Nutrition of the covid-19 patient in the intensive care unit (icu): A practical guidance. Crit. Care 2020, 24, 1-8. [CrossRef] [PubMed]

5. Martindale, R.; Patel, J.J.; Taylor, B.; Warren, M.; McClave, S.A. Nutrition therapy in the patient with covid-19 disease requiring icu care. Soc. Crit. Care Med. 2020, 1-8.

6. $\quad$ Singer, P.; Blaser, A.R.; Berger, M.M.; Alhazzani, W.; Calder, P.C.; Casaer, M.P.; Hiesmayr, M.; Mayer, K.; Montejo, J.C.; Pichard, C.; et al. Espen guideline on clinical nutrition in the intensive care unit. Clin. Nutr. 2019, 38, 48-79. [CrossRef] [PubMed]

7. Thibault, R.; Coeffier, M.; Joly, F.; Bohe, J.; Schneider, S.M.; Dechelotte, P. How the covid-19 epidemic is challenging our practice in clinical nutrition-feedback from the field. Eur. J. Clin. Nutr. 2021, 75, 407-416. [CrossRef]

8. Azzolino, D.; Passarelli, P.C.; D'Addona, A.; Cesari, M. Nutritional strategies for the rehabilitation of covid-19 patients. Eur. J. Clin. Nutr. 2021, 75, 728-730. [CrossRef]

9. Shanafelt, T.; Ripp, J.; Trockel, M. Understanding and addressing sources of anxiety among health care professionals during the covid-19 pandemic. JAMA 2020, 323, 2133-2134. [CrossRef]

10. Lai, J.; Ma, S.; Wang, Y.; Cai, Z.; Hu, J.; Wei, N.; Wu, J.; Du, H.; Chen, T.; Li, R.; et al. Factors associated with mental health outcomes among health care workers exposed to coronavirus disease 2019. JAMA Netw. Open 2020, 3, e203976. [CrossRef] [PubMed]

11. Cabana, M.D.; Rand, C.S.; Powe, N.R.; Wu, A.W.; Wilson, M.H.; Abboud, P.A.; Rubin, H.R. Why don't physicians follow clinical practice guidelines? A framework for improvement. JAMA 1999, 282, 1458-1465. [CrossRef]

12. Briassoulis, G.; Briassoulis, P.; Ilia, S. Nutrition is more than the sum of its parts. Pediatri. Crit. Care Med. J. Soc. Crit. Care Med. World Fed. Pediatri. Intensive Crit. Care Soc. 2018, 19, 1087-1089. [CrossRef]

13. Briassoulis, G.; Briassoulis, P.; Ilia, S. If you get good nutrition, you will become happy; if you get a bad one, you will become an icu philosopher. Pediatri. Crit. Care Med. J. Soc. Crit. Care Med. World Fed. Pediatri. Intensive Crit. Care Soc. 2019, 20, 89-90. [CrossRef]

14. Rees, E.M.; Nightingale, E.S.; Jafari, Y.; Waterlow, N.R.; Clifford, S.; CA, B.P.; Group, C.W.; Jombart, T.; Procter, S.R.; Knight, G.M. Covid-19 length of hospital stay: A systematic review and data synthesis. BMC Med. 2020, 18, 270. [CrossRef]

15. Bartsch, S.M.; Ferguson, M.C.; McKinnell, J.A.; O'Shea, K.J.; Wedlock, P.T.; Siegmund, S.S.; Lee, B.Y. The potential health care costs and resource use associated with covid-19 in the united states. Health Aff. 2020, 39, 927-935. [CrossRef]

16. Whittle, J.; Molinger, J.; MacLeod, D.; Haines, K.; Wischmeyer, P.E.; Group, L.-C.S. Persistent hypermetabolism and longitudinal energy expenditure in critically ill patients with covid-19. Crit. Care 2020, 24, 581. [CrossRef]

17. Arkin, N.; Krishnan, K.; Chang, M.G.; Bittner, E.A. Nutrition in critically ill patients with covid-19: Challenges and special considerations. Clin. Nutr. 2020, 39, 2327-2328. [CrossRef] 
18. Zhao, X.; Li, Y.; Ge, Y.; Shi, Y.; Lv, P.; Zhang, J.; Fu, G.; Zhou, Y.; Jiang, K.; Lin, N.; et al. Evaluation of nutrition risk and its association with mortality risk in severely and critically ill covid-19 patients. JPEN J. Parenter. Enter. Nutr. 2021, 45, 32-42. [CrossRef]

19. Haraj, N.E.; El Aziz, S.; Chadli, A.; Dafir, A.; Mjabber, A.; Aissaoui, O.; Barrou, L.; El Kettani El Hamidi, C.; Nsiri, A.; Al Harrar, R.; et al. Nutritional status assessment in patients with covid-19 after discharge from the intensive care unit. Clin. Nutr. ESPEN 2021, 41, 423-428. [CrossRef]

20. Lu, A.H.; Dollahite, J. Assessment of dietitians' nutrition counselling self-efficacy and its positive relationship with reported skill usage. J. Hum. Nutr. Diet. Off. J. Br. Diet. Assoc. 2010, 23, 144-153. [CrossRef] [PubMed]

21. Mayasari, N.R.; Ho, D.K.N.; Lundy, D.J.; Skalny, A.V.; Tinkov, A.A.; Teng, I.-C.; Wu, M.-C.; Faradina, A.; Mohammed, A.Z.M.; Park, J.M.; et al. Impacts of the covid-19 pandemic on food security and diet-related lifestyle behaviors: An analytical study of google trends-based query volumes. Nutrients 2020, 12, 3103. [CrossRef] [PubMed]

22. Zhang, J.; Rao, X.; Li, Y.; Zhu, Y.; Liu, F.; Guo, G.; Luo, G.; Meng, Z.; De Backer, D.; Xiang, H.; et al. Pilot trial of high-dose vitamin $\mathrm{C}$ in critically ill covid-19 patients. Ann. Intensive Care 2021, 11, 5. [CrossRef] [PubMed]

23. Hiedra, R.; Lo, K.B.; Elbashabsheh, M.; Gul, F.; Wright, R.M.; Albano, J.; Azmaiparashvili, Z.; Patarroyo Aponte, G. The use of iv vitamin c for patients with covid-19: A case series. Expert Rev. Anti-Infect. Ther. 2020, 18, 1259-1261. [CrossRef]

24. Azzolino, D.; Saporiti, E.; Proietti, M.; Cesari, M. Nutritional considerations in frail older patients with covid-19. J. Nutr. Health Aging 2020, 24, 696-698. [CrossRef] [PubMed]

25. Lawrence, V.; Hickson, M.; Weekes, C.E.; Julian, A.; Frost, G.; Murphy, J. A uk survey of nutritional care pathways for patients with covid-19 prior to and post-hospital stay. J. Hum. Nutr. Diet. Off. J. Br. Diet. Assoc. 2021. [CrossRef] [PubMed]

26. Buchanan, E.A.; Hvsizdak, E.E. Online survey tools: Ethical and methodological concerns of human research ethics committees. J. Empir. Res. Hum. Res. Ethics 2009, 4, 37-48. [CrossRef] [PubMed] 